\title{
STUDY OF THE GINGIVAL HEALTH IN CHILDREN WITH CROWN RESTORATIONS
}

\author{
Desislava Dimitrova $^{1}$, Radosveta Andreeva ${ }^{1}$, Mariana Dimova-Gabrovska ${ }^{2}$ \\ ${ }^{1}$ Department of Pediatric Dentistry, Faculty of Dental Medicine, \\ Medical University of Varna \\ ${ }^{2}$ Department of Prosthetic Dentistry, Faculty of Dental Medicine, \\ Medical University - Sofia
}

\begin{abstract}
INTRODUCTION: Prosthetic treatment with fixed constructions is an effective method for recovering severely destroyed teeth. The purpose of this study is to track the changes in the gingival tissues around teeth, which are prosthetically treated with different aesthetic crowns.

MATERIALS AND METHODS: Eighty-two teeth were studied with 46 of them being restored with CAD/ CAM composite crowns and 36 with ready-made zirconia crowns. The assessment of the condition of the surrounding soft tissues was performed using the modified gingival index (MGI).

RESULTS: Slight gingival inflammation of the severely destroyed natural teeth (MGI - $1,25 \div 2,13$ ) was reported, whereas after their restoration with crown constructions, healing processes and decreasing of the gingival index during the follow-up period occurred. The MGI, one year after placing the constructions, was $0 \div 1.44$.

CONCLUSION: CAD/CAM and ready-made zirconia crowns have excellent compatibility with surrounding soft tissues and do not disturb gingival health.
\end{abstract}

Keywords: crowns, childhood, gingival index

\section{INTRODUCTION}

Fixed crown prosthetic treatment is considered to be safe and successful method of restoring severe tooth decays due to caries and resulting complications $(1,2)$. Scientific studies $(3,4)$ testify for the high prophylactic value of the crown prosthetic treatment for secondary caries in saving the underlying den-

Address for correspondence:

Radosveta Andreeva

Faculty of Dental Medicine

84 Tzar Osvoboditel Blvd

9000 Varna

e-mail:doctor_ra@abv.bg

Received: June 3, 2018

Accepted: June 29, 2018 tal structures, protecting the dentin-pulp complex against contamination from the surrounding oral environment and preserving the vitality of the tooth in cases of inflammation. Aesthetic crowns used in cases of multi-surface caries lesions, proximal caries, high caries risk, early childhood caries, defects of the development of the tooth structures after pulpotomy or pulpectomy, fractured teeth, discolored teeth, and erosions provide the possibility of restoring adequate chewing and speech function and the aesthetic parameters of the dentition $(5,6)$.

According to some authors (7-10) plaque accumulation and the frequency of gingival inflammation around primary teeth restored with different types of crowns is negligible. A key factor in achieving optimal health results in the surrounding soft tissues is the good adaptation of the marginal edg- 
Desislava Dimitrova, Radosveta Andreeva, Mariana Dimova-Gabrovska

es of the crowns and the careful removal of the excess cement.

In modern literature, the impact of restorations with crowns made with CAD/CAM systems on the gingival health in children has not been fully investigated. All of this gave the authors a reason to carry out this research.

\section{AIM}

The aim of this study is to investigate the localized gingival inflammation around teeth restored with composite CAD/CAM crowns and ready-made zirconia crowns.

\section{MATERIALS AND METHODS}

Object of observation was localized gingival inflammation before and after restoring severely damaged teeth with 46 fixed crown constructions made by CAD/CAM system of composite material HIPC (Bredent, Germany) and 36 ready-made zirconia crowns (Nusmile, USA).

$\diamond$ Thirty-two (69.5\%) CAD/CAM crowns were used to restore the upper frontal segment of children, aged 3 to 5 years, with primary dentition and diagnosed with second and third stage of "early childhood caries".

$\diamond$ Another 14 (30.5\%) of the CAD/CAM crowns were used to restore teeth from the distal sections of primary and mixed dentitions in children aged 5 to 10 years.

$\diamond$ All 36 of the ready-made zirconia crowns were placed on primary teeth in the distal areas of the dentition in children aged 5 to 10 years

Due to the young age of the children and the risk of soft tissue trauma, for the study of gingival inflammation we used the proposed by Lobene et al. (11) modified gingival index (MGI), which does not apply a probe sample. The assessment is made only by visual inspection of the soft tissues around the prosthetically restored teeth.

The following criteria was used:

$\diamond 0$ - lack of inflammation

$\diamond 1$ - slight inflammation of any area of the gingiva with a slight change in color and texture

$\diamond 2$ - slight inflammation of the entire gingiva

$\diamond 3$ - moderate inflammation with smooth gingival edges, redness and swelling $\diamond 4$ - severe inflammation with clearly visible edema and redness and spontaneous bleeding The obtained values were summed and divided into the number of teeth examined and the following interpretations were made:

$\diamond$ score of 0 to 1 - the soft tissues around the tooth were considered healthy

$\diamond$ score of 1.1 to 4 - was considered as inflammation of the gingiva.

The study was performed before the prosthetic restoration, as well as 2 weeks, 2 months, 6 months, and 1 year after the crowns were placed.

\section{RESULTS}

A statistically significant difference in the mean values of the gingival index during the follow-up period $(\mathrm{P}<0.001)$ was observed. Regardless of the type of the used crowns, there was a tendency for decreasing values after the treatment compared to the values recorded before the beginning of the recovery. The best results were reported with the use of CAD/CAM crowns in the frontal area, where after one year in all patients with this type of constructions the gingival index was 0 . Close results were also found with the use of zirconia crowns, where in the first year after the treatment the mean of the MGI was 0.19 (Fig. 1).

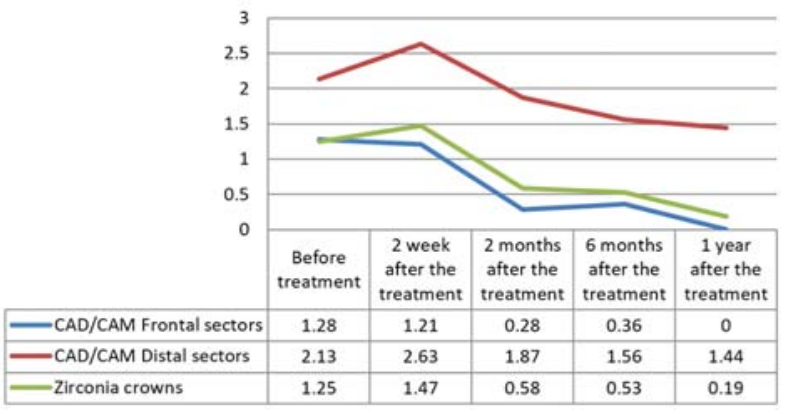

Fig. 1. Distribution of the gingival index according to the type of crowns used

The results of the study show that the MGI values correlate significantly with the type of the crowns used $(\mathrm{p}=0.856 ; \mathrm{p}<0.001)$. In $73.7 \%$ of the cases, the decreased values of the MGI were due to the type of constructions used. The best results were obtained with CAD/CAM crowns in the frontal area and zirconia crowns (Table 1). 
Study of the Gingival Health in Children with Crown Restorations

Table 1. Distribution of the gingival index before and after treatment with CAD/CAM crowns in the frontal areas

\begin{tabular}{lcc|c}
\multirow{2}{*}{ Period } & MGI after & \multicolumn{2}{c}{ MGI before treatment } \\
\cline { 3 - 4 } & treatment & $\mathbf{1}$ & $\mathbf{2}$ \\
\multirow{2}{*}{ 2 weeks } & $\mathbf{1}$ & 8 & 3 \\
\multirow{2}{*}{ 2 months } & $\mathbf{2}$ & 2 & 1 \\
\multirow{2}{*}{ 6 months } & $\mathbf{0}$ & 8 & 2 \\
\multirow{2}{*}{ 1 year } & $\mathbf{1}$ & 2 & 2 \\
\hline
\end{tabular}

\section{DISCUSSION}

The retention of pediatric crowns is achieved mainly due to the subgingival location of the marginal edges, which often is a cause of inflammatory changes in the surrounding soft tissues (12). According to Newcomb (13), the extent of gingival inflammation is directly related to the location of the preparation margins - more apical location is associated with deterioration in gingival health. Incorrect marginal contours of the crowns and inappropriate adaptation to the preparation lines are prerequisite for plaque retention, bacterial invasion in the dentinal tubules, mechanical irritation of the sulcus epithelium, secondary caries, and inflammation of the surrounding soft tissues $(14,15)$.

Because of its high biocompatibility and smooth polished surfaces, plaque accumulation in zirconia crowns is negligible and gingival inflammation is rarely detected $(16,17)$.

The results we obtained confirmed the data from previous clinical studies. A study by Walia et al. (10) tracked the healing processes in gingival tissues after restoring 43 teeth with zirconia crowns. Before the treatment, the MGI was $1.67 \pm 0.56$, whereas in the 6-month follow-up period there was a significant increase in gingival health indicators (MGI=1.35 \pm 0.6$)$. Data from other studies $(18,19)$ also testify for healing processes and lack of inflammation in soft tissues after zirconia crown application.

\section{CONCLUSION}

As a result of the data obtained, it can be concluded that CAD/CAM and ready-made zirconia crowns have excellent compatibility with the surrounding soft tissues and do not impair gingival health. However, the changes in the gingiva, after treatment with crowns, made by the method of digital design and machine milling, have not been fully studied. This necessitates additional research in the field.

\section{REFERENCES}

1. Norbert K, Lohbauer U, Frankenberger R. Restorative materials in the primary dentition of policaries patients. Eur Arc Paediatr Dent. 2007; 8(1): 29-35.

2. Rodd H, Waterhouse P, Fuks A, Fayle S, Moffat M. Pulp therapy for primary molars. Int J Paediatr Dent. 2006; 16(1):15-23.

3. Subramaniam P, Kondae S, Gupta KK. Retentive strength of lutting cements for stainless steel crowns: an in vitro study. Int J Clin Pediatr Dent. 2010; 34(4):309-12.

4. Tote J, Gadhane A, Das G, Soni S, Jaiswal K, Vidhale G. Posterior Esthetic Crowns in Peadiatric Dentistry. Int J Dent Med Res. 2015; 1(6):197-201.

5. O'Connell A, Kratunova E. Prefabricated Crowns for primary molars. How to achieve full coronal coverage in primary molar restorations. Scottish Dental. 2016.

6. Stines SM. Pediatric CAD-CAM applications for the general practicioner. Part 1. Dent Today. 2008; 27(130):2-3.

7. Vulicevic Z, Beloica M, Kosanovic D, Radovic I, Juloski J, Ivanovic D. Prosthetics in paediatric dentistry. Balk J Dent Med. 2017; 21:78-82.

8. Myers DR. A clinical study of the response of the gingival tissue surrounding stainless steel crowns. ASDC J Dent Child. 1975; 42:281-4.

9. Subramaniam P, Girish Babu KL, Gona H. Clinical outcome and parental satisfaction of maxillary anterior teeth treated with NuSmile preveneered crowns and Kinder Krowns. Saudi J Oral Sci. 2017; 4(2): 106-11.

10. Walia T, Salami A, Hamoodi O, Rashid F. A randomized controlled trial of three aesthetic full-coronal restorations in primary maxillary teeth. Eur J Paediatr Dent. 2014; 15(2): 113-8.

11. Lobene RR, Weatherford T, Ross NM, Lamm RA, Menaker L. A modified gingival index for use in clinical trials. Clin Prev Dent. 1986; 8(1): 3-6. 
12. Lee JK. Restoration of primary anterior teeth: a review of literature. Pediatr Dent. 2002; 24(5):506-11.

13. Newcomb GM. The relationship between the gingiva and the margin of restorations. J Clin Periodontol. 1974; 45(3):151-4.

14. Garg V, Panda A, Shah J, Panchal P. Crowns in peadiatric dentistry: a review. J Adv Med Dent Sci Res. 2016; 4(2): 41-6.

15. Haskins DR. Pediatric dental rehabilitation procedures in the OR. AORN J. 1996; 64(4): 573-9.

16. Bhola $M$, Jindal G. Revolution in pediatric restorative dentistry - zirconia crowns. J Stomatognathic Sci. 2016; 6(1): 22-6.

17. Cazaux L, Hyon I, Prud 'homme T, Trutaud D. Twenty-nine-month follow up of a paediatric zirconia dental crown. BMJ Case Rep. 2017; 2017-219891

18. Maclean JK, Champagne CE, Waggoner WF, Ditmyer MM, Casamassimo M. Clinical outcomes for primary anterior teeth treated with preveneered stainless steel crowns. Pediatr Dent. 2007; 29(6):377-81.

19. Schmitt J, Holst $S$, Wichmann M, Reich S, Gollner M, Hamel J. Zirconia posterior fixed dentures: A prospective clinical 3-year follow-up. Int J Prosthodont. 2009; 22(6): 597-603. 